\title{
Modeling and validation of Gatimaan Express with Matlab/Simulink
}

\author{
P. K. Jha \& S. S. Gokhale \\ Mechanical-Mechatronics Engineering Department, \\ The LNM Institute of Information Technology, India
}

\begin{abstract}
This paper presents modeling and validation of Gatimaan Express, a superfast train which will be running from New Delhi to Agra Cantonment at the speed of $160 \mathrm{kmph}$ and will cover $205 \mathrm{~km}$ in 105 minutes. It will have 12 air conditioned coaches with one locomotive class WAP5. In the current study, mathematical model with one locomotive class WAP5, one generator van, one second class chair car and one executive chair car is presented in this paper. The overall $152(4 \times 38)$ degree of freedom model is developed in Matlab/Simulink. The vertical and lateral track irregularities are the inputs to the system, based on ORE B176 standard with high rail irregularities. Research Designs and Standards Organisation (RDSO) provided data pertaining to the track geometry and velocity measurements as well as actual run data of lateral and vertical accelerations of locomotive WAP5, generator van, second class chair car and executive chair car. The vertical and lateral accelerations of locomotive, generator van, second class chair car and executive chair car of Gatimaan Express model are compared with the available measured sample data.

Keywords: longitudinal, lateral and vertical velocities and accelerations, track irregularities, coupling of a train, Matlab/Simulink.
\end{abstract}

\section{Introduction}

Many researchers have studied the lateral and vertical interactions between railway vehicle and track since last decades. Few of them are summarized in this section.

Sun and Dhanasekar [1] simulated a dynamics model of 10 degree of freedom to investigate the vertical interaction of track and vehicle. The model based on the nonlinear Hertz contact mechanism was validated with the field data. They 
concluded the primary suspension was more affected by wheel-rail impact rather than the secondary suspension.

Bayraktar et al. [2] presented a 19 degree of freedom of a model to analyze the variation of dynamic load on the axle, spring stiffness, rail quality and passenger coach load with speed. The simulated result was compared with the experimental data of German railways and found good agreement between them.

Tasai and $\mathrm{Wu}$ [3] designed a 28 degree of freedom of dynamic model and compared stability performances with test data of vehicle operated by Taipei Rapid Transit Corporation. The result was found satisfactory. They considered random inputs of various types of track irregularities in the model.

Demir [4] simulated a 3D model of 31 degree freedom of metro vehicle and determined the suspension parameters for the yaw stability of rail vehicle.

Ali Abood and Khan [5] designed a model of 31 degree of freedom which had lateral and vertical dynamics based on the combination of Kalker's theory and non linear heuristic creep theory. They identified suspension parameters which were primarily responsible for the ride comfort.

Jung et al. [6] also formulated 31 degree of freedom of a model and analyzed that the primary longitudinal and lateral stiffness are more responsible for the vehicle hunting speed. The model was based on two wheel-rail contact mechanism and heuristic creep theory.

Ranjbar and Ghazavi [7] presented a 38 degree of freedom model which had longitudinal, lateral, vertical, roll, pitch and yaw motions. The model was made on the heuristic nonlinear creep theory. They found that the critical hunting speed examined through the nonlinear elastic rail was lower than linear model.

Sezer and Erdem Ataly [8] developed a 54 degree of freedom railway vehicle model. They studied the dynamic response of the model due to the different rail irregularities.

From the literature survey, it can be concluded that various models with different degree of freedoms have been developed to study the interaction between the vehicle and track. The performance of suspension characteristics has been investigated. It can also be noted that most of models were having a single coach but in the present study, model is developed with one locomotive class WAP5, generator van, second class chair car and executive chair. It is assumed that actual Gatimaan Express is having same order of locomotive and carriages as stated in the model. Mathematical model of Gatimaan Express is developed in Matlab/Simulink. The lateral and vertical rail irregularities are the inputs for the simulation of model based on ORE B176 Power Spectral Density (PSD). The individual coach is treated as a point mass system. However mass, spring stiffness and damping coefficients of each coach may or may not be identical. The measured velocity and track geometry, provided by Testing Directorate and Track Machines and Monitoring Directorate of RDSO are incorporated into the model.

Roll, pitch, yaw speeds and longitudinal, lateral and vertical forces of the model are also discussed in this paper. 


\section{Mathematical model of Gatimaan Express}

Non conservative forces and elastic deformations produce creep between wheel and rail contact. Many researchers, Sezer and Erdem Ataly [8], Tsai and Wu [3], Demir [4] and Ali Abood and Khan [5] have developed rail vehicle models based on Newton's second law for a set of primary and secondary suspensions, creep forces (Kalker's theory), Hertz contact theory and normal forces. In this study, a single coach with 38 degree of freedom is developed and is further coupled with locomotive WAP5, generator van and executive chair car respectively. A schematic diagram of 38 degree of freedom of single coach of Gatimaan Express is shown in Figure 1. The longitudinal, lateral and vertical, roll, pitch and yaw motions are in set of differential equations. The pitch motion of wheelset is neglected in the current study.

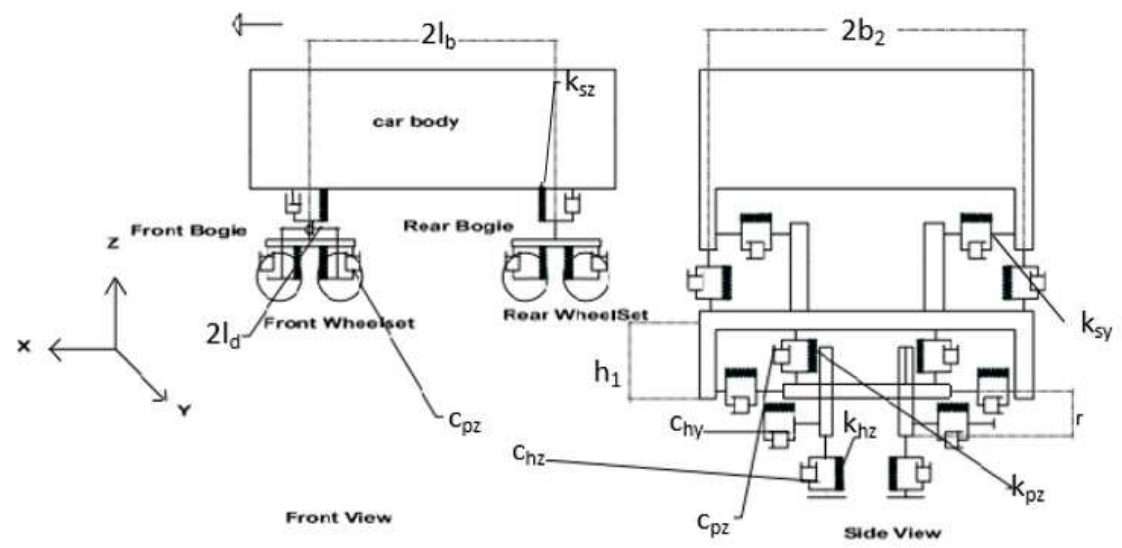

Figure 1: The 38 degree of freedom of Gatimaan Express model.

\subsection{Differential equations of car body motion}

A single coach is considered for mathematical analysis. The translatory and rotatory motions along and about longitudinal, lateral and vertical directions of the car body of the coach are derived as.

$$
\begin{aligned}
m_{c} \ddot{x_{c}} & +2 c_{s x}\left[2 \dot{x_{c}}-\left(\dot{x_{b 1}}+\dot{x_{b 2}}\right)\right]+2 k_{s x}\left[2 x_{c}-\left(x_{b 1}+x_{b 2}\right)\right]=0, \\
m_{c} \ddot{y_{c}} & -\left[\frac{v^{2}}{g R}-\phi_{s e}\right] m_{c} g+2 c_{s y}\left[2\left(\dot{y_{c}}+h_{3} \dot{\theta_{c}}\right)-\left(\dot{y_{b 1}}+\dot{y_{b 2}}\right)\right. \\
& \left.+h_{2}\left(\dot{\theta_{b 1}}+\dot{\theta_{b 2}}\right)\right]+2 k_{s y}\left[2\left(y_{c}+h_{3} \theta_{c}\right)-\left(y_{b 1}+y_{b 2}\right)\right. \\
& \left.+h_{2}\left(\theta_{b 1}+\theta_{b 2}\right)\right]+m_{c} g \theta_{c}=0,
\end{aligned}
$$




$$
\begin{aligned}
m_{c} \ddot{z}_{c} & +\left[1+\frac{v^{2}}{g R} \phi_{s e}\right] m_{c} g+2 c_{s z}\left[2 \dot{z_{c}}-\left(\dot{z_{b 1}}+z_{b 2}\right)\right] \\
& +2 k_{s z}\left[2 z_{c}-\left(z_{b 1}+z_{b 2}\right)\right]=0 \\
I_{x c} \ddot{\theta}_{c} & +2 h_{3} c_{s y}\left[2\left(h_{3} \dot{\theta_{c}}+\dot{y}_{c}\right)+h_{2}\left(\dot{\theta_{b 1}}+\dot{\theta_{b 1}}\right)-\left(\dot{y_{b 1}}+\dot{y_{b 2}}\right)\right] \\
& +2 b_{2}^{2} c_{s z}\left[2 \dot{\theta_{c}}-\left(\dot{\theta_{b 1}}+\dot{\theta_{b 1}}\right)\right] \\
& +2 h_{3} k_{s y}\left[2\left(h_{3} \theta_{c}+y_{c}\right)+h_{2}\left(\theta_{b 1}+\theta_{b 1}\right)-\left(y_{b 1}+y_{b 2}\right)\right] \\
& +2 b_{2}^{2} k_{s z}\left[2 \theta_{c}-\left(\theta_{b 1}+\theta_{b 1}\right)\right]-2 k_{a r}\left(2 \theta_{c}-\theta_{b 1}-\theta_{b 2}\right)+m_{c} g \theta_{c} h_{3}=0 \\
I_{y c} \ddot{\phi}_{c} & +2 l_{b} c_{s z}\left[2 l_{b} \dot{\phi_{c}}+\left(z_{\dot{b} 1}-z_{b 2}\right)\right]+2 l_{b} k_{s z}\left[2 l_{b} \phi_{c}+\left(z_{b 1}-z_{b 2}\right)\right]=0 \\
I_{z c} \ddot{\psi}_{c} & +2 l_{b} c_{s y}\left[2 l_{b} \dot{\psi_{c}}-h_{2}\left(-\dot{\theta_{b 1}}+\dot{\theta_{b 2}}\right)\right. \\
& \left.+\left(-y_{b 1}+y_{\dot{b} 2}\right)\right]+2 l_{b} k_{s y}\left[2 l_{b} \psi_{c}-h_{2}\left(-\theta_{b 1}+\theta_{b 2}\right)+\left(-y_{b 1}+y_{b 2}\right)\right] \\
& +2 d_{s}^{2}\left[k_{s x}\left(2 \psi_{c}-\left(\psi_{b 1}+\psi_{b 2}\right)\right)\right]=0 .
\end{aligned}
$$

\subsection{Differential equations for bogie motion}

A single coach is considered which has one car body and two bogies. The bogie consists of front and rear wheelsets. It is connected with the car body through secondary suspensions, and mechanical linkages with anti roll bar. The other end of bogie is connected with the wheelsets through primary suspensions and linkages. The differential equations of bogies for both car body and wheelsets connections in longitudinal, lateral and vertical directions are presented as follows:

$$
\begin{aligned}
& m_{b 1} \ddot{x_{b 1}}+2 k_{s x}\left[-x_{c}+x_{b 1}\right]+2 c_{s x}\left[-\dot{x_{c}}+\dot{x_{b 1}}\right] \\
& \quad+2 k_{p x}\left[2 x_{b 1}-\left(x_{w 1}+x_{w 1}\right)\right]+2 c_{p x}\left[2 \dot{x_{b 1}}-\left(x_{w 1}+x_{w 1}\right)\right]=0, \\
& m_{b 1} \ddot{y_{b 1}}-\left[\frac{v^{2}}{g R}-\phi_{s e}\right]\left(m_{c} / 2+m_{b 1}\right) g+2 c_{s y}\left(-\dot{y}_{c}\right. \\
& \left.\quad+y_{\dot{b} 1}-h_{3} \dot{\theta_{c}}-h_{2} \dot{\theta_{b 1}}-l_{b} \dot{\psi_{c}}\right)+2 k_{s y}\left(-y_{c}+y_{b 1}-h_{3} \theta_{c}-h_{2} \theta_{b 1}\right. \\
& \left.\quad-l_{b} \psi_{c}\right)+2 c_{p y}\left[2 y_{\dot{b} 1}-y_{\dot{w} 1}-y_{w 2}+2 h_{1} \dot{\theta_{b 1}}\right]+2 k_{p y}\left[2 y_{b 1}\right. \\
& \left.\quad-y_{w 1}-y_{w 2}+2 h_{1} \theta_{b 1}\right]=0, \\
& m_{b 1} \ddot{z_{b 1}}+\left[1+\frac{v^{2}}{g R} \phi_{s e}\right]\left(m_{c} / 2+m_{b 1}\right) g+2 c_{p z}\left[2 z_{b 1}\right. \\
& \left.\quad-\left(z_{\dot{w} 1}+z_{\dot{w} 2}\right)\right]+2 k_{p z}\left[2 z_{b 1}-\left(z_{w 1}+z_{w 2}\right)\right] \\
& +2 c_{s z}\left[\left(-\dot{z_{c}}+z_{\dot{b} 1}+l_{b} \dot{\phi_{c}}\right)\right]+2 k_{s z}\left[\left(-z_{c}+z_{b 1}+l_{b} \phi_{c}\right)\right]=0,
\end{aligned}
$$




$$
\begin{aligned}
& I_{x b 1} \ddot{\theta_{b 1}}+2 h_{1} c_{p y}\left[2\left(h_{1} \dot{\theta_{b 1}}+\dot{y_{b 1}}\right)-\dot{y_{w 1}}-\dot{y_{w 2}}\right]+2 h_{1} k_{p y}\left[2 \left(h_{1} \theta_{b 1}\right.\right. \\
& \left.\left.\quad+y_{b 1}\right)-y_{w 1}-y_{w 2}\right]+2 h_{2} c_{s y}\left[h_{3} \dot{\theta_{c}}+h_{2} \dot{\theta_{b 1}}+\dot{y_{c}}-\dot{y_{b 1}}+l_{b} \dot{\psi_{c}}\right] \\
& \quad+2 h_{2} k_{s y}\left[h_{3} \theta_{c}+h_{2} \theta_{b 1}+y_{c}-y_{b 1}\right. \\
& \left.\quad+l_{b} \psi_{c}\right]+2 b_{1}^{2} c_{p z}\left(2 \dot{\theta_{b 1}}-\dot{\theta_{w 1}}-\dot{\theta_{w 2}}\right)+2 b_{1}^{2} k_{p z}\left(2 \theta_{b 1}-\theta_{w 1}-\theta_{w 2}\right) \\
& \quad+2 b_{2}^{2} c_{s z}\left(-\dot{\theta_{c}}+\dot{\theta_{b 1}}\right)+2 b_{2}^{2} k_{s z}\left(-\theta_{c}+\theta_{b 1}\right) \\
& \quad-k_{a r}\left(-\theta_{c}+\theta_{b 1}\right)=0 \\
& \quad \ddot{\phi_{b 1}}+2 l_{d} c_{p z}\left[2 l_{d} \dot{\phi_{b 1}}+z_{\dot{w} 1}-z_{\dot{w} 2}\right]+2 l_{d} k_{p z}\left[2 l_{d} \phi_{b 1}\right. \\
& \left.\quad+z_{w 1}-z_{w 2}\right]=0 \\
& \quad \ddot{\phi_{b 1}}+2 d_{p}^{2} c_{p x}\left[2 \dot{\psi_{b 1}}-\dot{\psi_{w 1}}-\dot{\psi_{w 2}}\right]+2 d_{p}^{2} k_{p x}\left[2 \psi_{b 1}-\right. \\
& \left.\quad \psi_{w 1}-\psi_{w 2}\right]+2 d_{s}^{2} k_{s x}\left[\psi_{b 1}-\psi_{c}\right]+2 d_{s}^{2} c_{s x}\left[\dot{\psi_{b 1}}\right. \\
& \left.\quad-\dot{\psi_{c}}\right]+2 l_{d} c_{p y}\left[2 l_{d} \dot{\psi_{b 1}}-\dot{y_{w 1}}+\dot{y_{w 2}}\right] \\
& \quad+2 l_{d} k_{p y}\left[2 l_{d} \psi_{b 1}-y_{w 1}+y_{w 2}\right]=0 .
\end{aligned}
$$

The above equations are derived for front bogie.

\subsection{Differential equations for wheelset motion}

The wheelset is having two wheels fixed with an axle. Forces for primary suspension and creep during the contact with rail are developed below. The rail excitation along the vertical and lateral are also considered.

$$
\begin{aligned}
& m_{w 1} \ddot{x_{w 1}}+2 c_{p x}\left[-x_{b 1}+x_{w 1}\right]+2 k_{p x}\left[-x_{b 1}+x_{w 1}\right] \\
& \quad+\left[2 f_{33}(-a) \frac{\dot{\psi_{w 1}}}{v}\right]=0 \\
& m_{w 1} \ddot{y_{w 1}}-\left[\frac{v^{2}}{g R}-\phi_{s e}\right]\left(m_{c} / 4+m_{b 1} / 2+W+m_{w 1}\right) g \\
& \quad+\dot{y_{w 1}} \frac{2 f_{11}}{v}-2 f_{11} \psi_{w 1} \\
& \quad+\left(m_{c} / 4+m_{b 1} / 2+W+m_{w 1}\right) g \theta_{w 1}+\dot{\psi_{w 1}} \frac{2 f_{12}}{v} \\
& \quad+\theta_{w 1} \frac{2 f_{11} r}{v}+2 c_{p y}\left[-\dot{y_{b 1}}+\dot{y_{w 1}}-h_{1} \dot{\theta_{b 1}}-l_{d} \dot{\psi_{b 1}}\right] \\
& \quad+2 k_{p y}\left[-y_{b 1}+y_{w 1}-h_{1} \theta_{b 1}-l_{d} \psi_{b 1}\right] \\
& +c_{h y}\left[-\dot{y_{r 1}}+\dot{y_{w 1}}+r \dot{\theta}_{w 1}\right]+k_{h y}\left[-y_{r 1}+y_{w 1}+r \theta_{w 1}\right]=0
\end{aligned}
$$


446 Computers in Railways XV: Railway Engineering Design and Operation

$$
\begin{aligned}
& m_{w 1} z_{w 1}^{.}+\left[1+\frac{v^{2}}{g R} \phi_{s e}\right]\left(m_{c} / 4+m_{b 1} / 2+W+m_{w 1}\right) g \\
& +\lambda^{2} \dot{\theta}_{w 1} \psi_{w 1} y_{w 1} \frac{2 f_{11}}{v} \\
& +\dot{y_{w 1}} \frac{2 f_{11}}{v} \theta_{w 1}+\theta_{w 1} \dot{\psi_{w 1}} \frac{2 f_{12}}{v}-\lambda^{2} \frac{2 f_{12}}{r}+\psi_{w 1} \theta_{w 1} \frac{2 f_{11} r}{v} \\
& +2 c_{p y}\left[-\dot{y}_{b 1}+\dot{y}_{\dot{w} 1}-h_{1} \dot{\theta_{b 1}}\right. \\
& \left.-l_{d} \dot{\psi_{b 1}}\right]+c_{h y}\left[-\dot{y_{r 1}}+\dot{y_{w 1}}+r \dot{\theta}_{w 1}\right]+k_{h y}\left[-y_{r 1}+y_{w 1}+r \theta_{w 1}\right]=0 \text {, } \\
& I_{x w 1} \ddot{\theta_{w 1}}+2 b_{1}^{2} c_{p z}\left[-\dot{\theta_{b 1}}+\dot{\theta_{w 1}}\right] \\
& +2 b_{1}^{2} k_{p z}\left[-\theta_{b 1}+\theta_{w 1}\right]+a c_{h z}\left[2 a \theta_{w 1}^{\cdot}\right. \\
& \left.+\dot{z_{r 1}}-\dot{z_{r 2}}\right]+a k_{h z}\left[2 a \theta_{w 1}+z_{r 1}-z_{r 2}\right]+\lambda r a \frac{2 f_{11}}{v} \dot{\theta}_{w 1}+r^{2} \frac{2 f_{11}}{v} \dot{\theta_{w 1}} \\
& +r \dot{y_{w 1}} \frac{2 f_{11}}{v}+a \lambda \dot{y_{w 1}} \frac{2 f_{11}}{v}+r \dot{\psi_{w 1}} \frac{2 f_{12}}{v}-\frac{v}{r} I_{y_{w} 1} \dot{\psi_{w 1}} \\
& +\lambda a \dot{\psi_{w 1}} \frac{2 f_{12}}{v}-2 \lambda^{2} f_{12} \theta_{w 1}+a \lambda\left(m_{c 1} / 4+m_{b 1} / 2+m_{w 1}+W\right) g \theta_{w 1} \\
& -\lambda^{4}\left(m_{c 1} / 4+m_{b 1} / 2+m_{w 1}+W\right) g y_{w 1} \frac{2 f_{12}}{r} \\
& -\lambda^{2} \psi_{w 1} \frac{2 f_{22}}{v}-2 \psi_{w 1} f_{11} r-\psi_{w 1} 2 f_{11} a \lambda=0, \\
& I_{z w 1} \ddot{\psi_{w 1}}+2 d_{p}^{2} c_{p} x\left[\dot{\psi_{w 1}}-\dot{\psi_{b 1}}\right]+2 d_{p}^{2} k_{p} x\left[\psi_{w 1}-\psi_{b 1}\right]+2 f_{12} \psi_{w 1} \\
& -\dot{y_{w 1}} \frac{2 f_{12}}{v}+\frac{2 f_{22} \dot{\psi_{w 1}}}{v}+a^{2} \theta_{w 1} \frac{2 f_{33}}{v} \\
& +\theta_{w 1} \frac{2 f_{33}}{v}-r \dot{\theta} \cdot \frac{2 f_{12}}{v}+\theta_{w 1}^{\cdot} \frac{I_{y w 1} v}{r} \\
& +2 f_{12} \psi_{w 1}+\left(m_{c} / 4+m_{b 1} / 2+W+m_{w 1}\right) a \lambda g \psi_{w 1}-a \lambda y_{w 1} \frac{2 f_{33}}{r}=0 .
\end{aligned}
$$

The above equations are derived for front wheelset.

\subsection{Coupling of locomotive WAP5, generator van, second class chair car and executive chair car}

Combining the locomotive WAP5, generator van, second class chair and executive chair car with the help of couplers to make a train as shown in Figure 2. Longitudinal connection is considered in the mathematical modeling of the train. $m_{c 1}, m_{c 2}, m_{c 3}, m_{c 4}$ are masses, $c_{1}, c_{2}, c_{3}, k_{1}, k_{2}$ and $k_{3}$ are coupler linear damping and linear spring coefficients of locomotive WAP5, generator van, second class chair and executive chair car respectively. The equations for coupling the train are derived below: 


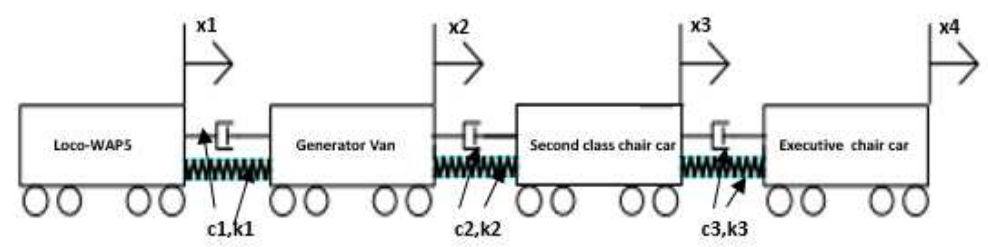

Figure 2: Schematic diagram of coupling of Gatimaan Express model.

Equation of motion for locomotive WAP5:

$$
m_{c 1} \ddot{x_{1}}+c_{1}\left[\dot{x_{1}}-\dot{x_{2}}\right]+k_{1}\left[x_{1}-x_{2}\right]=0 .
$$

Equation of motion for generator van:

$$
m_{c 2} \ddot{x_{2}}+c_{1}\left[\dot{x_{2}}-\dot{x_{1}}\right]+k_{1}\left[x_{2}-x_{1}\right]+c_{2}\left[\dot{x_{2}}-\dot{x_{3}}\right]+k_{2}\left[x_{2}-x_{3}\right]=0 .
$$

Equation of motion for second class chair car:

$$
m_{c 3} \ddot{x_{3}}+c_{1}\left[\dot{x_{3}}-\dot{x_{2}}\right]+k_{1}\left[x_{3}-x_{2}\right]+c_{3}\left[\dot{x_{3}}-\dot{x_{4}}\right]+k_{3}\left[x_{3}-x_{4}\right]=0 .
$$

Equation of motion for executive chair car:

$$
m_{c 4} \ddot{x_{4}}+c_{3}\left[\dot{x_{4}}-\dot{x_{3}}\right]+k_{3}\left[x_{4}-x_{3}\right]=0 .
$$

\section{Development of Gatimaan Express model in Matlab/ Simulink}

Presented masses to Gatimaan Express model for the simulation as below:

Locomotive WAP5 : $566510 \mathrm{~kg}$

Generator van : $38115 \mathrm{~kg}$

Second class chair car : $43590 \mathrm{~kg}$

Executive chair car : $41940 \mathrm{~kg}$

The derived differential equations of the car body, bogies and wheelsets are presented in Matlab/Simulink with its version of R2015b applying Runge Kutta ode 45 order solver and time step of 0.001 second with the absolute tolerances 1e-03. The layout of Gatimaan model is shown in Figure 3. The track curve from Agra Cantonment to Palwal and measured velocities are incorporated in the model. There are 54 curves and their respective super elevation. The super elevation is provided to cancel out the centrifugal force while moving along curve.

Key features of the curved track are as below:

Right: radius $3500 \mathrm{~m}$ and cant angle 0.0238 radian ( + sign in equations $2,3,8$, 9, 14 and 15).

Left: radius $3365.4 \mathrm{~m}$ and cant angle 0358 radian radian ( - sign in equations 2 , $3,8,9,14$ and 15). 


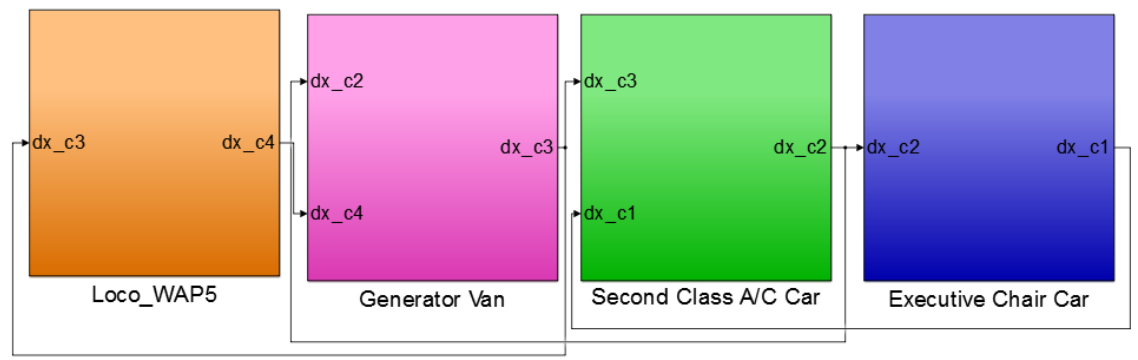

Figure 3: The layout of Simulink model of a complete model of Gatimaan Express.

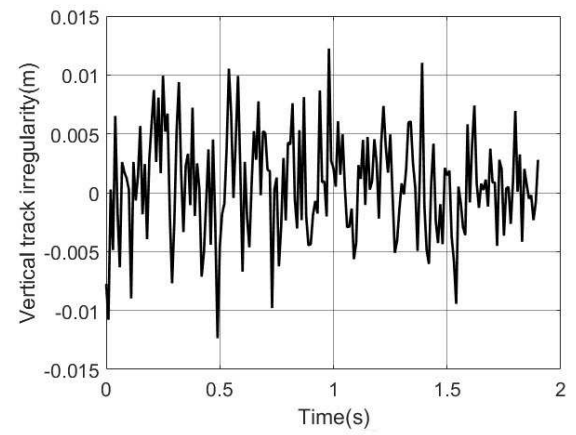

(a) Vertical track irregularity

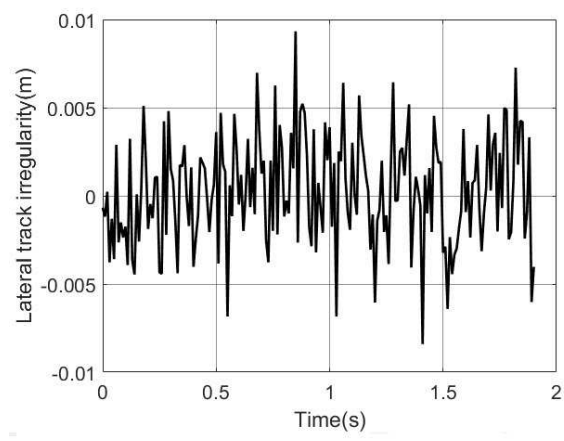

(b) Lateral track irregularity

Figure 4: Track irregularity.

The simulation is done for a set of tracks which is having straight track, right curve track, again straight track and finally left curve track.

The measured sample data of lateral and vertical accelerations of locomotive WAP 5, generator van, second class chair car and executive chair car of Gatimaan Express during the travel from New Delhi to Agra Cantonment was recorded for 


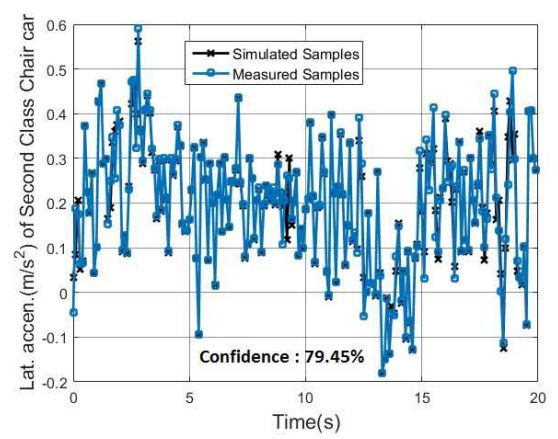

(a) Lateral accelerations of Second Class Chair Car

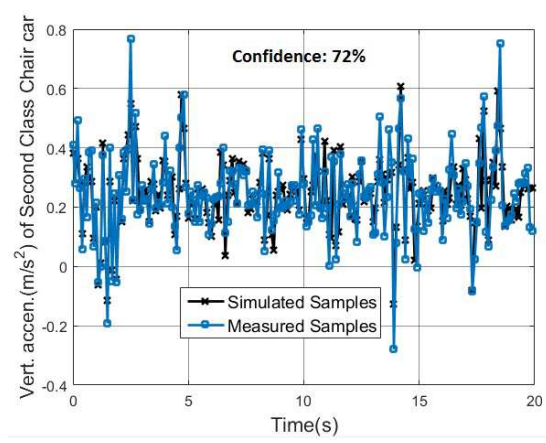

(b) Vertical accelerations of Second Class Chair Car

Figure 5: Lateral and vertical accelerations of Second Class Chair for 20 seconds of simulation.

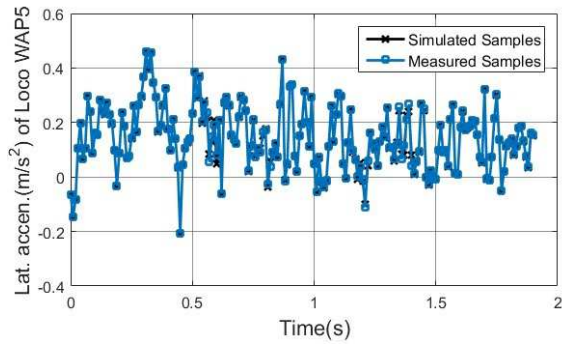

(a) Lateral accelerations of Loco WAP5

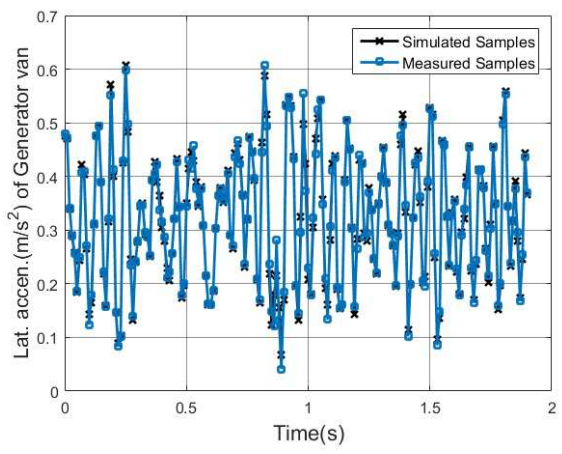

(b) Lateral accelerations of Generator Van

Figure 6: Lateral accelerations. 


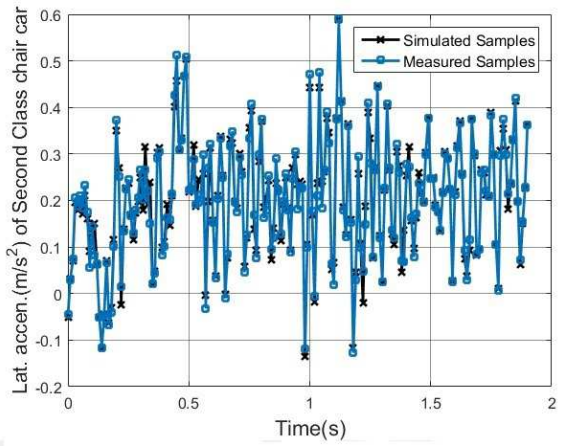

(a) Lateral accelerations of Second Class Chair Car

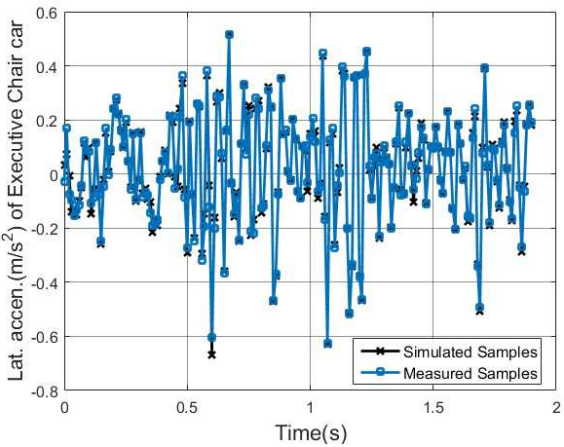

(b) Lateral accelerations of Executive Chair Car

Figure 7: Lateral accelerations contd.

Table 1: Lateral accelerations.

\begin{tabular}{|c|c|}
\hline Lateral acceleration & Confidence (\%) \\
\hline Loco WAP5 & 94.07 \\
\hline Generator Van & 88.79 \\
\hline Second Class Chair Car & 83.69 \\
\hline Executive Chair Car & 90.44 \\
\hline
\end{tabular}

Table 2: Vertical accelerations.

\begin{tabular}{|c|c|}
\hline Vertical acceleration & Confidence (\%) \\
\hline Loco WAP5 & 87.33 \\
\hline Generator Van & 91.07 \\
\hline Second Class Chair Car & 78.86 \\
\hline Executive Chair Car & 87.14 \\
\hline
\end{tabular}

$17 \mathrm{~km}$. These accelerations with speed of Gatimaan Express was recorded in real time by using LabView of National Instruments at sampling rate 100 samples per second.

The response of these irregularities are shown in Figures 4(a) and 4(b). The simulation is run for 20 seconds but the performances of Gatimaan Express model are shown for 2 seconds in subsequent figures for clarity. Compared simulated results with measured data of lateral and vertical accelerations of second class chair car for 20 seconds run of simulation are shown in Figures 5(a) and 5(b).

The simulated results of the lateral and vertical accelerations of locomotive WAP5, generator van, second class chair car and executive chair car are compared with respective measured acceleration sample data and are shown in Figures 6(a), 6(b), 7(a), 7(b), 8(a), 8(b), 9(a), 9(b) respectively.

The simulated accelerations are estimated through the Hammerstein-Wiener model to get best curve fit with their respective measured accelerations. It is shown that there is good match between the simulated results and measured sample data. The confidence level percentage in curve fitting of lateral and vertical accelerations of model are shown in Tables 1 and 2. 


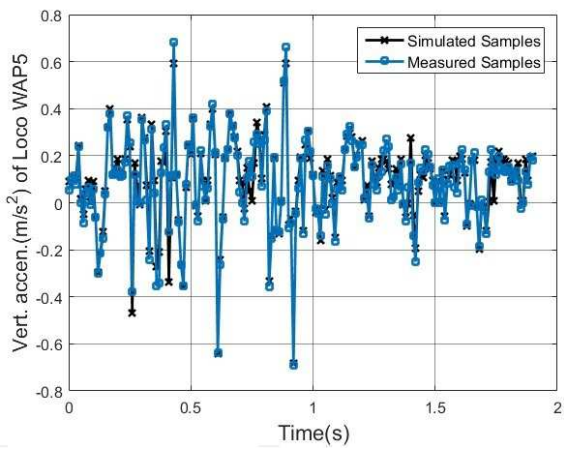

(a) Vertical accelerations of Loco WAP5

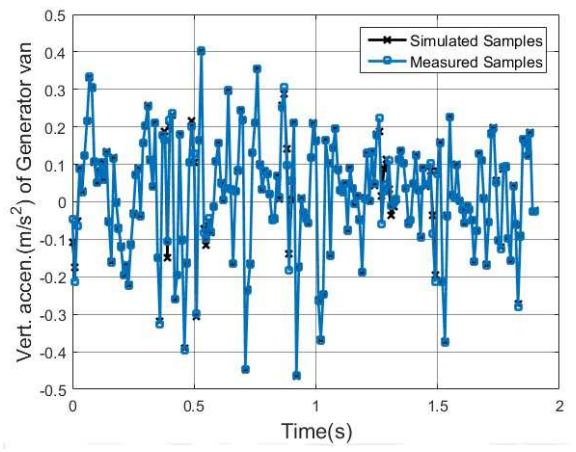

(b) Vertical accelerations of Generator Van

Figure 8: Vertical accelerations.
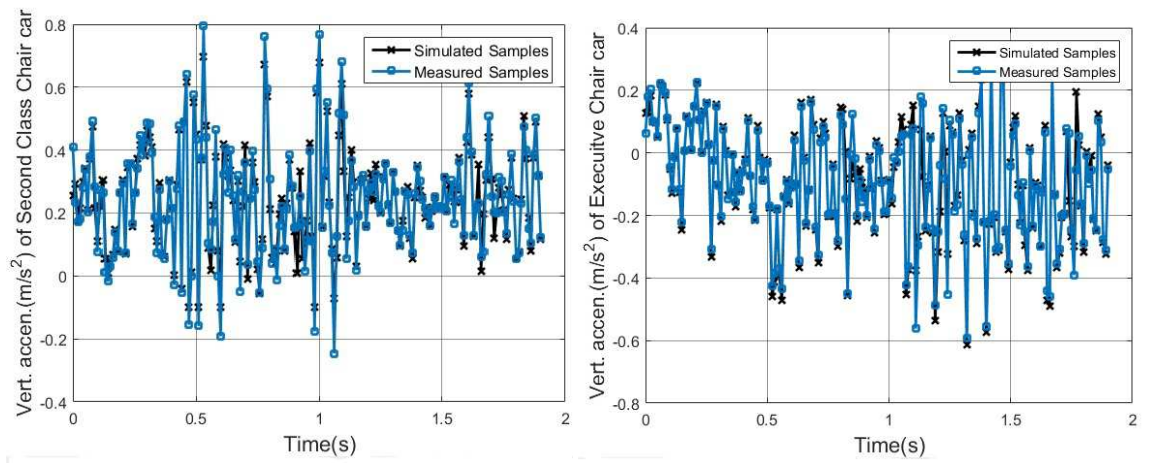

(a) Vertical accelerations of Second Class Chair Car (b) Vertical accelerations of Executive Chair Car

Figure 9: Vertical accelerations contd.

The roll motions, pitch motions and yaw motions of WAP5, generator van, second class chair car and executive chair car are shown in Figures 10, 11, 12 respectively. A harmonic oscillations can be seen in their performances.

The simulated longitudinal, lateral and vertical suspension fores of WAP5, generator van, second class chair car and executive chair car are express in Figures 13,14, 15. The longitudinal suspension forces of the model are less than the lateral and vertical suspension forces.

Because of the vehicle speed, track geometry and track irregularities, there are variations in the three dimensional forces. These variations should be under certain limit otherwise, the train can be derailed as it crosses the limit. The major input parameter values are incorporated to the model are listed in Table 3. 

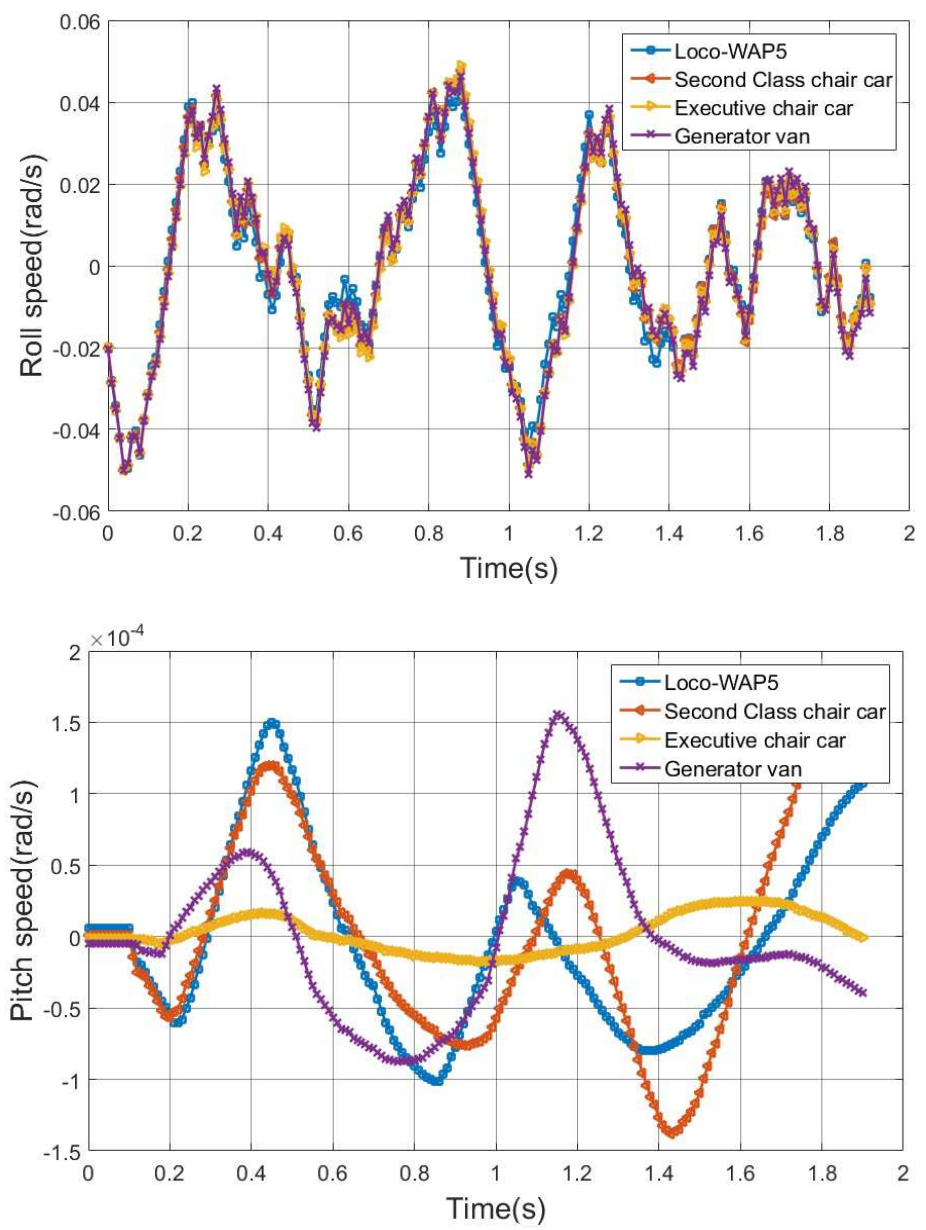

Figure 11: Pitch motion.

\subsection{Conclusion and remarks}

The dynamic model of Gatimaan Express, having locomotive WAP5, generator van, second class chair car and executive chair car is developed in Matlab/Simulink successfully. The various masses of model are considered, keeping spring stiffness and damping coefficients constants. The model is exposed to rail irregularities along the lateral and vertical directions to excite vibration in it on the tangential and curvilinear tracks. The simulated lateral and vertical accelerations of the model are in good match with the measured sample data. The sharp peaks in both lateral and vertical dynamics are observed which are due to track geometry, track irregularities. 


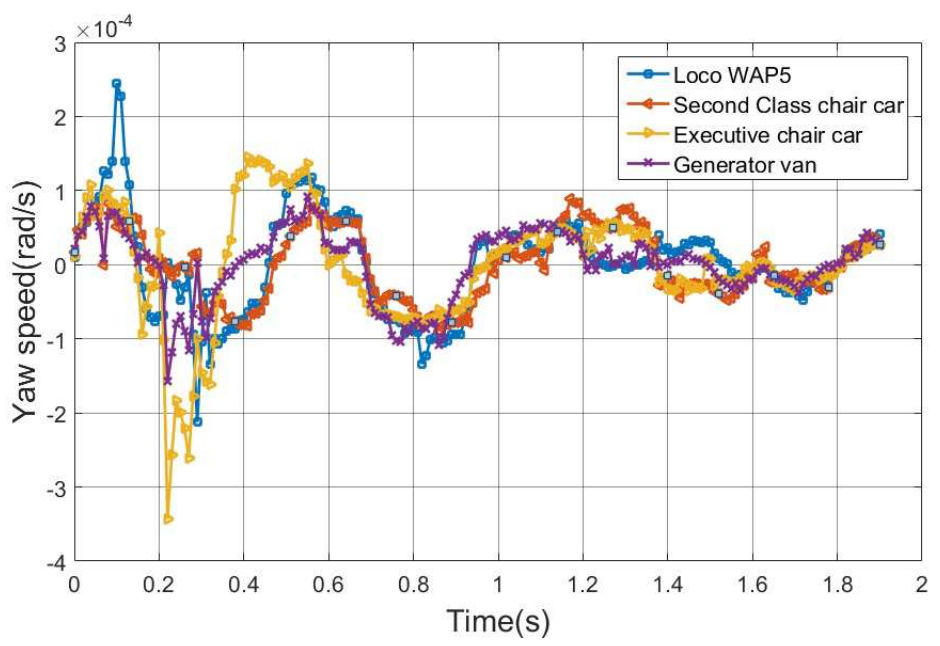

Figure 12: Yaw motion.

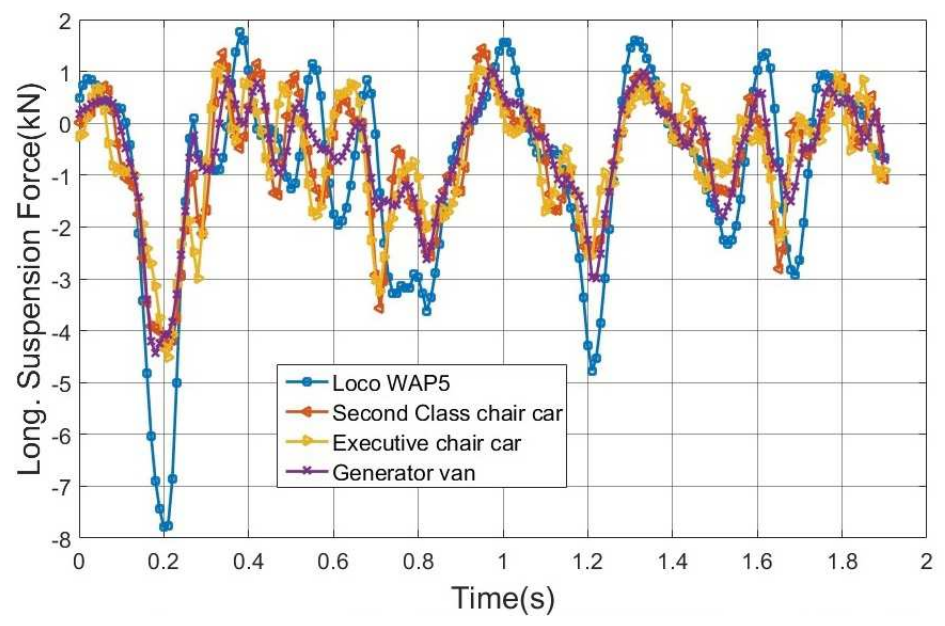

Figure 13: Longitudinal suspension force.

The lateral, roll and yaw motions of rail vehicle are more responsible for hunting than the vertical and pitch dynamics.

The model can also be studied for lateral stability and hunting behavior. Further the derailment dynamics can be analyzed as there is suspension damage. It can affect the ratio of lateral and vertical force and finally cause for the derailment. 


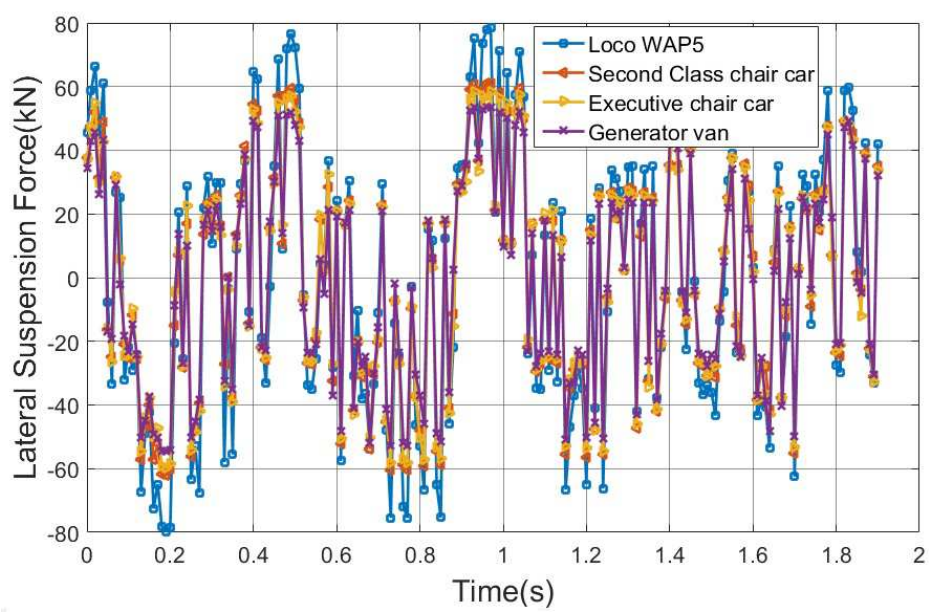

Figure 14: Lateral suspension force.

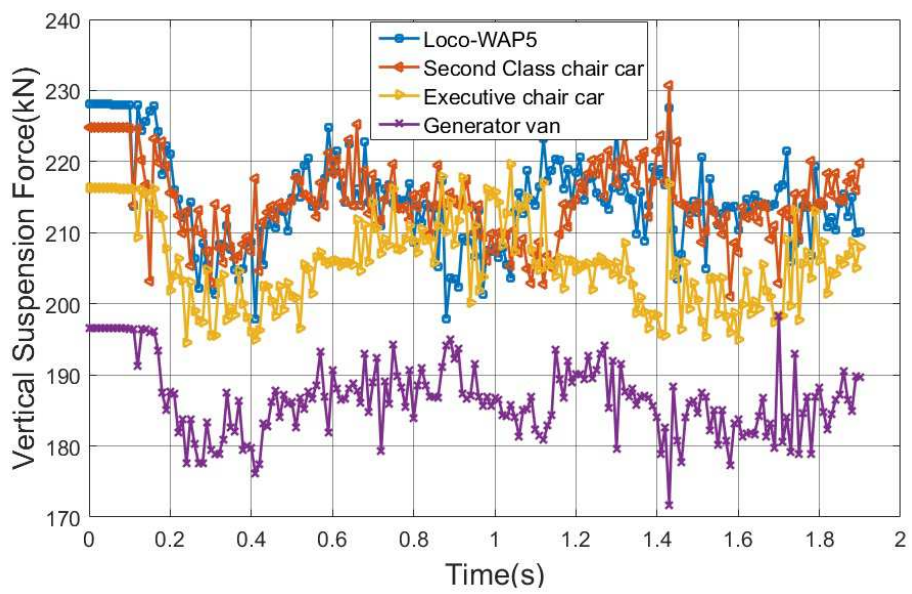

Figure 15: Vertical suspension force.

\section{Future work}

The model can be made more robust by adding the impact of the vertical and lateral dynamics of neighbor coaches. The hunting and critical performances of car body and wheelset will be analyzed. The extensive work of train dynamics including coupling of train with different spring stiffness and damping coefficients for locomotive WAP5, generator van, second class chair car and executive chair car and derailment dynamics can be performed. 
Table 3: List of parameters assumed for simulation.

\begin{tabular}{|l|l|l|}
\hline$m_{c}=37740[\mathrm{~kg}]$ & $m_{b}=3000[\mathrm{~kg}]$ & $m_{w}=1600[\mathrm{~kg}]$ \\
\hline$I_{x c}=56932\left[\mathrm{~kg} / \mathrm{m}^{2}\right]$ & $I_{y c}=1307220\left[\mathrm{~kg} / \mathrm{m}^{2}\right]$ & $I_{z c}=1309744\left[\mathrm{~kg} / \mathrm{m}^{2}\right]$ \\
\hline$I_{x b}=1713\left[\mathrm{~kg} / \mathrm{m}^{2}\right]$ & $I_{y b}=3206\left[\mathrm{~kg} / \mathrm{m}^{2}\right]$ & $I_{z b}=4763\left[\mathrm{~kg} / \mathrm{m}^{2}\right]$ \\
\hline$I_{x w}=1271\left[\mathrm{~kg} / \mathrm{m}^{2}\right]$ & $I_{y w}=3206\left[\mathrm{~kg} / \mathrm{m}^{2}\right]$ & $I_{z w}=1271\left[\mathrm{~kg} / \mathrm{m}^{2}\right]$ \\
\hline$c_{p x}=10000000[\mathrm{Ns} / \mathrm{m}]$ & $c_{p y}=500000[\mathrm{Ns} / \mathrm{m}]$ & $c_{p z}=2000000[\mathrm{Ns} / \mathrm{m}]$ \\
\hline$k_{p x}=10000000[\mathrm{~N} / \mathrm{m}]$ & $k_{p y}=2500000000[\mathrm{~N} / \mathrm{m}]$ & $k_{p z}=1000000000[\mathrm{Ns} / \mathrm{m}]$ \\
\hline$c_{s x}=100000[\mathrm{Ns} / \mathrm{m}]$ & $c_{s y}=2150000[\mathrm{Ns} / \mathrm{m}]$ & $c_{s z}=311000[\mathrm{Ns} / \mathrm{m}]$ \\
\hline$k_{s x}=10000000[\mathrm{~N} / \mathrm{m}]$ & $k_{s y}=2250000[\mathrm{~N} / \mathrm{m}]$ & $k_{s z}=3500000[\mathrm{~N} / \mathrm{m}]$ \\
\hline$k_{h z}=350000000[\mathrm{~N} / \mathrm{m}]$ & $c_{h z}=200000[\mathrm{~N} / \mathrm{m}]$ & $c_{h y}=5700000[\mathrm{~N} / \mathrm{m}]$ \\
\hline$l_{b}=7.45[\mathrm{~m}]$ & $l_{d}=0.9[\mathrm{~m}]$ & $d_{p}=0.9[\mathrm{~m}]$ \\
\hline$d_{s}=0.85[\mathrm{~m}]$ & $a=0.838[\mathrm{~m}]$ & $b_{1}=0.5[\mathrm{~m}]$ \\
\hline$b_{2}=0.85[\mathrm{~m}]$ & $r=0.452[\mathrm{~m}]$ & $h_{1}=0.2[\mathrm{~m}]$ \\
\hline$h_{2}=0.2[\mathrm{~m}]$ & $h_{3}=0.73[\mathrm{~m}]$ & $f_{11}=103318[\mathrm{~N}]$ \\
\hline$f_{12}=11334[\mathrm{Nm}]$ & $f_{33}=1260500[\mathrm{~N}]$ & $f_{22}=61.56[\mathrm{~N}]$ \\
\hline$k_{a r}=250000[\mathrm{~N} / \mathrm{mrad}]$ & $W=14977.57[\mathrm{~kg}]$ & $m_{c 1}=566510[\mathrm{~kg}]\left(150 \%\right.$ of $\left.m_{c}\right)$ \\
\hline$m_{c 2}=38115[\mathrm{~kg}]\left(115 \%\right.$ of $\left.m_{c}\right)$ & $m_{c 3}=43590[\mathrm{~kg}]\left(111 \%\right.$ of $\left.m_{c}\right)$ & $m_{c 4}=41940[\mathrm{~kg}]\left(101.1 \%\right.$ of $\left.m_{c}\right)$ \\
\hline
\end{tabular}

\section{Acknowledgements}

The author would like to thank Testing Directorate and Track Machines and Monitoring Directorate, RDSO for providing the measured data during test run of Gatimaan Express and track geometry for New Delhi-Agra Cantonment Route.

\section{Nomenclature}

$b_{1}$ : lateral distance between vertical primary suspension and corresponding wheelset origin $[\mathrm{m}]$

$b_{2}$ : lateral distance between vertical secondary suspension and coach mass center $[m]$

$d_{p}$ : lateral distance between a longitudinal primary suspension and corresponding wheelset origin $[\mathrm{m}]$

$d_{s}$ : lateral distance between longitudinal secondary suspension and corresponding bogie origin $[m]$

$l_{b}$ : longitudinal distance between bogies and coach mass center $[\mathrm{m}]$

$l_{d}$ : longitudinal distance between center of two wheelset $[\mathrm{m}]$

$h_{1}$ : vertical distance between wheelset and bogie mass centers $[\mathrm{m}]$ 
$h_{2}$ : vertical distance between bogie mass center and lateral secondary suspension $[m]$

$h_{3}$ : vertical distance between lateral secondary suspension and car body mass center $[m]$

$c_{s x}, c_{s y}$ and $c_{s z}$ : long., lateral and vertical Secondary damping coefficients $[N s / m]$

$c_{p x}, c_{p y}$ and $c_{p z}$ : long., lateral and vertical Primary damping coefficients $[\mathrm{N} / \mathrm{m}]$

$k_{p x}, k_{p y}$ and $k_{p z}$ : long., lateral and vertical Primary spring coefficients $[N / m]$

$k_{s x}, k_{s y}$ and $k_{s z}$ : long., lateral and vertical Secondary spring coefficients $[N / m]$

$c_{h z}$ and $c_{h y}$ : vertical and lateral hertz damping coefficient $[N / m]$

$k_{h z}$ and $k_{h y}$ : vertical and lateral hertz spring coefficient $[\mathrm{N} / \mathrm{m}]$

$I_{x b}, I_{y b}$ and $I_{z b}$ : roll, pitch and yaw mass moment of inertia of bogie $\left[\mathrm{kg} / \mathrm{m}^{2}\right]$

$I_{x c}, I_{y c}$ and $I_{z c}$ : roll, pitch and yaw mass moment of inertia of car body $\left[\mathrm{kg} / \mathrm{m}^{2}\right]$

$I_{x w}, I_{y w}$ and $I_{z w}$ : roll, pitch and yaw mass moment of inertia of wheelset $\left[\mathrm{kg} / \mathrm{m}^{2}\right]$

$m_{c}, m_{b}$, and $m_{w},:$ mass of car body, bogie and wheelset $[\mathrm{kg}]$

$r$ and $R$ : nominal wheel radius and radius of track $[\mathrm{m}]$

$z_{r}$ and $y_{r}$ : vertical and lateral track excitation $[m]$

$\theta_{c}, \theta_{b}, \theta_{w}$ : roll displacement of car body, bogie and wheelset [ $\left.\mathrm{rad}\right]$

$\phi_{c}$ and $\phi_{b}$ : pitch displacement of car body and bogie $[\mathrm{rad}]$

$\psi_{c}, \psi_{b}$ and $\psi_{w}$ : yaw displacement of car body, bogie and wheelset [rad]

$\lambda$ : wheel profile conicity $[\mathrm{rad}]$

$a$ : half of track gauge $[\mathrm{m}]$

$f_{11}$ : lateral creep coefficient $[N]$

$f_{12}$ : lateral/spin creep coefficient $\left[\mathrm{Nm}^{2}\right]$

$f_{33}$ : spin creep coefficient $[N]$

$f_{22}$ : longitudinal creep coefficient $[N]$

$k_{a r}$ : anti roll stiffness coefficient $[N /$ mrad $]$

\section{References}

[1] Y. Q. Sun and M. Dhanasekar. A dynamics model for the vertical interaction of the rail track and wagon system. International Journal of Solids and Structures, 39(1):1337-1359, 2002.

[2] M. Bayraktar, F. Dikmen and R. Guclu. Dynamic analysis of rail vehicle axle. Indian Academy of Science, 38(2): 265-280, 2013.

[3] F. Y. Tsai and W. F. Wu. Stability analysis of railway vehicles and its verifications through field test data. Journal of the Chinese Institute of Engineers, 29(3): 493-505, 2006.

[4] E. Demir. 3D suspension characterization of a metro vehicle. In Proc. of the Int. Conf. on Advanced railway Engineering, pages 13-30, Istanbul, 2015.

[5] K. H. Ali Abood and R. A. Khan. Railway carriage to study the influence of vertical secondary stiffness on ride comfort of railway car body running on curved tracks. Journal of Modern Applied Science, 5(2): 11-24, 2011.

[6] J. Jung, P. Kim and J. Seok. A parametric dynamics study on hunting 
stability of full duel-bogie railway vehicle. International Journal of Precision Engineering and Manufacturing, 12(3): 505-519, 2011.

[7] M. Ranjbar and M. R. Ghazavi. Lateral stability analysis of high speed railway vehicle on curve. In Proc. of the Int. conf. of Advances robotics, measured engineering, mechanical engineering and design, pages 11-14, 2012.

[8] S. Sezer and A. Erdem Ataly. Dynamic modeling and fuzzy logic control of vibrations of a railway vehicle for different track irregularities. Simulation Modelling Practice and Theory, 19(1): 1873-1894, 2011. 